\title{
Rapid cervical phIGFBP-1 test in asymptomatic twin pregnancies is inefficient in predicting preterm delivery prior to 34 gestational weeks
}

\author{
Katarzyna Kosińska-Kaczyńska, Iwona Szymusik, Dorota Bomba-Opoń, \\ Aleksandra Zyguła, Mirosław Wielgoś \\ ${ }^{15 t}$ Chair and Department of Obstetrics and Gynecology, Medical University of Warsaw, Poland
}

\begin{abstract}
Objectives: To assess the effectiveness of a rapid second trimester test for cervical phIGFBP-1 in the prediction of spontaneous preterm delivery prior to 34 weeks in asymptomatic twin pregnancies.

Material and methods: A prospective observational study conducted on 232 twin pregnancies tested for phIGFBP-1 at 20-24 weeks of gestation. 151 patients assessed as asymptomatic, with cervical length $>25 \mathrm{~mm}$ at 20-24 weeks were analysed. The primary outcome was the delivery $<34$ weeks of gestation.

Results: The spontaneous preterm delivery before completing 34 weeks occurred in 23 patients (15.2\%), including 9 in dichorionic and $14 \mathrm{in} \mathrm{monochorionic} \mathrm{pregnancies.} \mathrm{The} \mathrm{sensitivity} \mathrm{of} \mathrm{phIGFBP-} 1$ test was 0.39 and specificity 0.63 in predicting delivery before 34 gestational weeks. phIGFBP- 1 had a low positive predictive value of 0.16 and high negative predictive value (0.85). Both positive and negative predictive values of delivery $<34$ weeks were close to 1.

Conclusions: A test for phIGFBP1 presence is not an effective additional tool for predicting preterm delivery before 34 weeks in twin gestation.
\end{abstract}

Key words: twin pregnancy, preterm birth, IGFBP test, preterm delivery screening tests, multiple gestation

Ginekologia Polska 2018; 89, 6: 321-325

\section{INTRODUCTION}

Preterm delivery affects about $2 / 3$ of all twin pregnancies and accounts for about $50 \%$ of all neonatal deaths [1-5]. In the Preterm Prediction Study, 54.4\% of all twins were born prior to 37 weeks, $32 \%$ before 35 weeks and $8.8 \%$ before completing 32 weeks of gestation [3]. The problem of prematurity in a constantly growing number of twins increases the social and public health expenses, however the biggest medical problems and financial outlays are intended for twins born before 34 gestational weeks [6]. Several biochemical markers have been proposed to predict preterm delivery in both symptomatic and asymptomatic pregnant women, including cervical phosphorylated insulin-like growth factor binding protein-1 (phIGFBP-1). IGFBP-1 is a 25-kDa hydrophobic protein [7]. Its phosphorylated form is produced mainly by decidual cells and is present between the chorion and decidua. When the cervix matures for delivery, the chorion and decidua detach and phIGFBP-1 leeks into the cervical secretion. In 2001 Kekki et al. reported that phIGFBP-1 presence in cervical secretion is a predictor of preterm delivery [8]. A commercial bedside test for phIGFBP-1 is available in Europe. In comparison to fetal fibronectin (fFN) it has the advantage of being unaffected by recent sexual intercourse or urine presence, and the cost of the test is lower $[8,9]$. Its efficiency as a predictor of preterm delivery in singleton pregnancies has been widely discussed in the literature [10-12]. phIGFBP-1 is especially useful in identifying symptomatic women in singleton pregnancies who will not deliver within 48 hours [10]. However, its efficacy in the prediction of preterm delivery in twin gestations is uncertain. 


\section{Objectives}

The aim of our study was to assess the effectiveness of a rapid test for cervical phIGFBP-1 performed in the second trimester in the prediction of spontaneous preterm delivery before 34 gestational weeks in asymptomatic twin pregnancies.

\section{MATERIAL AND METHODS}

A prospective observational study was conducted at the $1^{\text {st }}$ Department of Obstetrics and Gynecology, Medical University of Warsaw, between 2012 and 2015. 232 women prior to 16 weeks of twin gestation were enrolled after giving an informed written consent. Gestational age and chorionicity were confirmed in the first trimester ultrasound scan. There were 84 women in monochorionic diamniotic and 148 in dichorionic pregnancies. Patients in monoamniotic pregnancies were initially excluded from the study due to a specific risk of preterm delivery. Women in dichorionic pregnancies were counselled routinely once every 4 weeks and in monochorionic pregnancies once every 2 weeks, including an ultrasound scan. In cases with no pregnancy complications both monochorionic and dichorionic twins were delivered beyond 37 weeks of gestation according to the local policy. During the observational period 7 patients miscarried and 6 had twin-to-twin transfusion syndrome (TTTS), therefore they were excluded from further analysis. All women were counselled between 20 and 24 weeks of gestation. A routine ultrasound scan assessing fetal biometry and anatomy were performed during that period and an ultrasound measurement of the length of cervical canal was performed. It was measured according to Fetal Medicine Foundation recommendations - transvaginal probe was placed in the anterior fornix of the vagina with an empty bladder and the linear distance between calipers placed at the internal and external cervical os was taken. At the same time, between 20 and 24 gestational weeks, cervical swab samples were collected with a special kit and the presence of phIGFBP-1 was evaluated by an immunoenzymometric assay (Actim Partus, Medix Biochemica). According to the manufacturer the test is positive when phIGFBP-1 reaches the concentration of $10 \mu \mathrm{g} / \mathrm{L}$. Cervical secretion samples were obtained by inserting a sterile swab into the cervical canal for 15 seconds. The swab was swirled in the extraction solution for 10 seconds. After the extraction the test dipstick was placed in the solution. It was checked after five minutes: if the two lines (control line and test line) appeared, the test was considered positive. If only test line appeared, the test was negative. There were no cases of failed tests with no test line visible.

There were 20 patients diagnosed with cervical length less than $25 \mathrm{~mm}$ between 20 and 24 gestational weeks and they had Arabin pessary inserted and/or vaginal progester- one administered. In 1 case of amniotic membranes protruding through external os of the cervix a rescue cerclage was performed. In 2 cases preterm premature rupture of membranes occurred prior to 24 weeks of gestation and in 2 other intrauterine fetal demise was diagnosed. In order to avoid bias all those patients were further excluded from the analysis. No clinical interventions were introduced on the basis of the analyzed phIGFBP-1 test results.

The primary outcome of the study was delivery occurring before completed 34 weeks of gestation. Secondary outcomes included deliveries prior to 37 (preterm delivery) and 32 weeks of gestation. In order to minimize bias all patients delivered before 37 completed weeks due to medical indications were also excluded from the study. Only patients who developed spontaneous regular uterine contractions and afterwards delivered both vaginally and via caesarean section were taken into analysis. Six patients were lost to follow-up. Finally there were 151 asymptomatic patients eligible for analysis - none of them were administered vaginal progesterone. The diagram illustrating the study population is presented in Figure 1.

The following variables were included in the analysis: patients'age, parity, chorionicity, pre-pregnancy body mass index (BMI), gestational weight gain, the use of assisted reproduction techniques (ART), gestational age at testing, ultrasound assessment of cervical length and gestational age at delivery. Data on pregnancy outcome and delivery were obtained from hospital records. BMI was calculated by dividing the body mass by the square of the body height. Gestational weight gain was calculated by subtraction of the pre-gravid weight from final weight measured before delivery.

The study obtained the approval of the Ethics Committee of Medical University of Warsaw and was conducted according to the Declaration of Helsinki.

Variables are described as mean $( \pm S D)$, median or percentage. The Mann-Whitney test (for continuous variables)

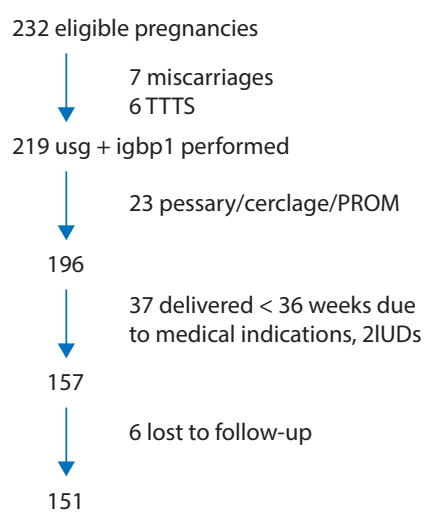

Figure 1. The flow chart of studied population 
and the Fisher's exact test (for percentages) were used for the statistical analysis. p-values $<0.05$ were considered significant. Sensitivity, specificity, positive predictive value, negative predictive value and positive and negative likelihood ratio with $95 \%$ confidence intervals were calculated to test the predictive value for preterm delivery (before 32, 34 and 37 weeks of gestation) of the phIGFBP-1 test. Data were analysed using Statistica version 13.1.

\section{RESULTS}

The mean gestational age at testing for phIGFBP- 1 was 22.4 weeks (20-24 weeks). The mean gestational age at delivery was 35.4 weeks. The spontaneous preterm delivery before completing 34 weeks occurred in 23 patients (15.2\%), including 9 in dichorionic and 14 in monochorionic pregnancies. 93 patients delivered before 37 gestational weeks (61.6\%), 9 prior to 32 weeks $(6 \%)$ and 2 patients before 28 weeks of gestation (1.3\%). In the group of dichorionic twin pregnancies 56 (58.3\%) were delivered before 37,9 (9.2\%) before 34, 4 (4.1\%) before 32 and none before 28 weeks of gestation. Among monochorionic twins delivery before 37 weeks occurred in 37 cases $(69.8 \%)$, before 34 weeks in 14 cases (26.4\%), before 32 weeks in 11 cases (20.8\%) and before 28 in 2 cases (3.8\%). Basic characteristics of patients studied and those delivering $<34$ and $\geq 34$ weeks are presented in Table 1.

Patients delivering $<34$ weeks of gestation had shorter cervical length on mid-trimester ultrasound scan, but the difference was on the border of statistical significance $(p=0.05)$ and similar occurrence of positive phIGFBP-1 test between 20 and 24 weeks to those delivering beyond 34 we- eks $(p=0.8)$. Women delivering beyond 37 gestational weeks had significantly longer cervical length on ultrasound scan ( $p=0.02)$ and less often positive phIGFBP-1 test $(p<0.001)$.

In the study group 56 patients were tested positive for IGFBP-1 (37.1\%). 46 of them delivered preterm spontaneously (82.1\%), $9<34$ weeks ( $16.1 \%), 5<32$ weeks (8.9\%) and $2<28$ weeks of gestation (3.6\%). Among 95 women with negative IGFBP-1 test 47 delivered before completing 37 weeks of gestation (49.5\%), $14<34$ weeks ( $14.7 \%), 4<32$ weeks (4.2\%) and none $<28$ gestational weeks.

The performance of the phIGFBP-1 test in predicting preterm delivery is reported in Table 2 . The sensitivity was 0.39 and specificity 0.63 in predicting delivery before 34 gestational weeks. phIGFBP-1 had a low positive predictive value (PPV) of 0.16 and high negative predictive value $(0.85)$. Both positive and negative predictive values of delivery $<34$ weeks were close to 1. phIGFBP-1 had similar performance of the test in predicting PTD in monochorionic, as well as dichorionic pregnancies. The test had moderate sensitivity (0.5) and high specificity (0.83) in prediction of delivery before 37 weeks. Having a positive phIGFBP-1 test in mid-pregnancy has a positive predictive value of 2.87 of delivering before 37 gestational weeks.

\section{DISCUSSION}

This study proves that phIGFBP-1 test has a low sensitivity if performed between 20 and 24 weeks of gestation in predicting delivery before 34 weeks in asymptomatic women in twin gestation. Although the negative predictive value (NPV) for the delivery < 34 weeks was high (0.85), it

Table 1. Basic characteristics of the study group and group of patients delivering $<34$ and $\geq 34$ weeks

\begin{tabular}{|c|c|c|c|c|c|c|c|}
\hline & \multicolumn{2}{|c|}{$\begin{array}{l}\text { Study group } \\
\qquad n=151\end{array}$} & \multicolumn{2}{|c|}{$\begin{array}{l}\text { Delivery } \geq 34 \text { weeks } \\
\qquad n=128\end{array}$} & \multicolumn{2}{|c|}{$\begin{array}{c}\text { Delivery }<34 \text { weeks } \\
n=23\end{array}$} & \multirow[b]{2}{*}{$\mathbf{p}$} \\
\hline & $\begin{array}{l}\text { average } \pm \text { SD } \\
\quad * n(\%)\end{array}$ & $95 \% \mathrm{Cl}$ & $\begin{array}{l}\text { average } \pm \text { SD } \\
*^{*}(\%)\end{array}$ & $95 \% \mathrm{Cl}$ & $\begin{array}{l}\text { average } \pm \text { SD } \\
*^{*}(\%)\end{array}$ & $95 \% \mathrm{Cl}$ & \\
\hline Age (years) & $30.8 \pm 4.1$ & $30.1-31.4$ & $30.7 \pm 4.2$ & $30-31.55$ & $31.2 \pm 3.4$ & $29.8-32.6$ & 0.6 \\
\hline Primiparous* & $93(61.6 \%)$ & & $74(57.8 \%)$ & & $19(82.6 \%)$ & & 0.02 \\
\hline Multiparous* & $58(38.4 \%)$ & & $54(42.2 \%)$ & & $4(17.4 \%)$ & & 0.02 \\
\hline $\begin{array}{l}\text { Chorionicity: } \\
\text { Dichorionic* } \\
\text { Monochorionic* }\end{array}$ & $\begin{array}{l}98(64.9 \%) \\
53(35.1 \%)\end{array}$ & & $\begin{array}{l}89(69.5 \%) \\
39(30.5 \%)\end{array}$ & & $\begin{array}{c}9(39.1 \%) \\
14(60.9 \%)\end{array}$ & & 0.008 \\
\hline $\mathrm{BMI}\left[\mathrm{kg} / \mathrm{m}^{2}\right]$ & $23.4 \pm 3.9$ & $22.8-24$ & $23.7 \pm 3.9$ & $23-24.4$ & $21.8 \pm 3.3$ & $20.3-23.2$ & 0.04 \\
\hline Gestational weight gain [kg] & 17.6 & $16.7-18.5$ & $18.1 \pm 4.9$ & $17.3-19$ & $14.5 \pm 7.3$ & $11.4-17.7$ & 0.002 \\
\hline $\mathrm{ART}^{*}$ & $42(27.8 \%)$ & & $37(28.9 \%)$ & & $5(21.7 \%)$ & & 0.4 \\
\hline Cervical length (mm) & $34.2 \pm 4.8$ & $33.5-35$ & $35 \pm 4.7$ & $33.8-35.4$ & $32 \pm 5.1$ & $29.7-34.3$ & 0.05 \\
\hline Positive phIGFB-1 test* & $56(37.1 \%)$ & & 47 (36.7\%) & & $9(39.1 \%)$ & & 0.8 \\
\hline Caesarean delivery* & $127(84.1 \%)$ & & $104(81.3 \%)$ & & $23(100 \%)$ & & \\
\hline
\end{tabular}

SD — standard deviation; $95 \% \mathrm{Cl}$ — 95\% coefficient interval; BMI — body mass index; ART — pregnancies after assisted reproductive techniques 
Table 2. Sensitivity, specificity, positive predictive value (PPV), negative predictive value (NPV), positive likelihood ratio (+LR+) and negative likelihood ratio (-LR) of phosphorylated insulin-like growth factor binding protein-1 (phlGFBP-1) for spontaneous delivery $<34,<37$ and $<32$ weeks of gestation

\begin{tabular}{|c|c|c|c|c|c|c|}
\hline & $\begin{array}{c}\text { Sensitivity } \\
(95 \% \mathrm{Cl})\end{array}$ & $\begin{array}{c}\text { Specificity } \\
(95 \% \mathrm{Cl})\end{array}$ & $\begin{array}{c}\text { Positive } \\
\text { predictive value } \\
\text { (PPV) } \\
(95 \% \mathrm{Cl})\end{array}$ & $\begin{array}{c}\text { Negative } \\
\text { predictive value } \\
\text { (NPV) } \\
(95 \% \mathrm{Cl})\end{array}$ & $\begin{array}{c}\text { Positive } \\
\text { likelihood ratio } \\
\text { (+LR) } \\
(95 \% \mathrm{Cl})\end{array}$ & $\begin{array}{c}\text { Negative } \\
\text { likelihood ratio } \\
(-\mathrm{LR}) \\
(95 \% \mathrm{Cl})\end{array}$ \\
\hline \multicolumn{7}{|c|}{ Study group $(n=151)$} \\
\hline \multicolumn{7}{|c|}{ Delivery $<34$} \\
\hline phIGFBP-1 & $0.39(0.21-0.6)$ & $0.63(0.6-0.67)$ & $0.16(0.09-0.25)$ & $0.85(0.81-0.9)$ & $1.07(0.53-1.81)$ & $0.96(0.6-1.31)$ \\
\hline \multicolumn{7}{|c|}{ Delivery $<37$} \\
\hline phIGFBP-1 & $0.5(0.43-0.54)$ & $0.83(0.73-0.91)$ & $0.82(0.72-0.9)$ & $0.5(0.44-0.55)$ & $2.87(1.57-5.7)$ & $0.61(0.51-0.79)$ \\
\hline \multicolumn{7}{|c|}{ Delivery $<32$} \\
\hline phIGFBP-1 & $0.53(0.28-0.77)$ & $0.65(0.62-0.67)$ & $0.14(0.08-0.21)$ & $0.93(0.89-0.96)$ & $1.51(0.74-2.36)$ & $0.72(0.34-1.16)$ \\
\hline \multicolumn{7}{|c|}{ Dichorionic pregnancies $(n=98)$} \\
\hline \multicolumn{7}{|c|}{ Delivery $<34$} \\
\hline phIGFBP-1 & $0.11(0.01-0.48)$ & $0.67(0.66-0.71)$ & $0.03(0.01-0.14)$ & $0.89(0.87-0.93)$ & $0.34(0.02-1.64)$ & $1.32(0.74-1.5)$ \\
\hline \multicolumn{7}{|c|}{ Delivery $<37$} \\
\hline phIGFBP-1 & $0.43(0.34-0.49)$ & $0.86(0.74-0.94)$ & $0.8(0.64-0.91)$ & $0.53(0.46-0.58)$ & $3(1.33-7.73)$ & $0.67(0.55-0.89)$ \\
\hline \multicolumn{7}{|c|}{ Delivery $<32$} \\
\hline phIGFBP-1 & $0.25(0.01-0.78)$ & $0.69(0.68-0.71)$ & $0.03(0.01-0.1)$ & $0.96(0.94-0.99)$ & $0.81(0.04-2.71)$ & $1.09(0.3-1.45)$ \\
\hline \multicolumn{7}{|c|}{ Monochorionic pregnancies $(n=53)$} \\
\hline \multicolumn{7}{|c|}{ Delivery $<34$} \\
\hline phIGFBP-1 & $0.57(0.32-0.8)$ & $0.54(0.45-0.62)$ & $0.31(0.17-0.43)$ & $0.78(0.65-0.89)$ & $1.24(0.59-2.09)$ & $0.8(0.33-1.51)$ \\
\hline \multicolumn{7}{|c|}{ Delivery $<37$} \\
\hline phIGFBP-1 & $0.59(0.49-0.66)$ & $0.75(0.51-0.91)$ & $0.85(0.7-0.95)$ & $0.44(0.31-0.45)$ & $2.38(1.01-7.46)$ & $0.54(0.37-0.99)$ \\
\hline \multicolumn{7}{|c|}{ Delivery $<32$} \\
\hline phIGFBP-1 & $0.64(0.34-0.87)$ & $0.55(0.47-0.61)$ & $0.27(0.14-0.37)$ & $0.85(0.73-0.95)$ & $1.41(0.64-2.22)$ & $0.66(0.21-1.41)$ \\
\hline
\end{tabular}

was similar to the rate of deliveries $<34$ weeks in the study group (15.2\%), suggesting no additional benefits in clinical practice. The results were similar in both monochorionic and dichorionic groups separately.

According to our results the risk of preterm delivery was $61.6 \%$. In patients with positive result of IGFBP-1 test the probability of delivery before 37 weeks has risen almost 3-times, while in patients with negative test results the risk has decreased to $37.6 \%$. Patients in dichorionic pregnancies with positive test were 3-times more likely to deliver preterm, while patients in monochorionic pregnancies about 2.4-times more likely to deliver before 37 weeks of gestation.

Although the efficacy of phIGFBP-1 test in prediction of preterm delivery has been widely studied, the data on its effectiveness among patients in twin gestation is scarce. Several studies included women both in singleton and twin gestations, however separate results for twin pregnancies were not presented $[8,13-16]$. There are only two published researches on twins. In 2010 Adeyemi and Osoba published a retrospective study including patients in twin pregnancies. 40 asymptomatic women had phIGFBP-1 test perfor- med at 26 weeks of gestation. According to their results the patients with a negative phIGFBP-1 test had a low risk of delivery before 34 weeks in the absence of other obstetric complications, as only $7.5 \%$ of all women with a negative test result delivered $<34$ weeks of gestation. Only 2 women had a positive test result (5\%) - one of them delivered $<34$ weeks and the other $>37$ weeks of gestation [17].

The second research by Fichera et al. was a prospective cohort study published in 2014. 197 asymptomatic women in twin pregnancies were tested for phIGFBP-1 at the time of ultrasound fetal anatomy scan. $10.7 \%$ of patients delivered $<34$ gestational weeks. Reported phIGFBP-1 test sensitivity and specificity for the delivery $<34$ weeks were 0.14 and 0.92 , respectively. Neither positive nor negative test result changed the risk of the delivery $<34$ weeks significantly. Positive and negative likelihood ratios were both inadequate for clinical use (+LR 1.79, 95\% Cl: 0.56-5.74; -LR $0.93,95 \% \mathrm{Cl}: 0.78-1.1)$ [18]. In our study the percentage of patients delivering $<34$ weeks was similar (15.2\%) and the test result also did not significantly change the risk of the delivery $<34$ weeks, as both positive and negative likeli- 
hood ratios were similar to those reported by Fichera et al. (+LR 1.07, 95\% Cl: 0.53-1.81; -LR 0.96, 95\% Cl: 0.6-1.31). Similar performance of the test was found for the delivery prior to 32 weeks. In both above mentioned studies NPV was high and varied between 0.9 and 0.97 for the delivery $<34$ and $<28$ weeks. Our data are consistent with these results (NPV $0.85-0.93$ for the delivery $<34$ and $<32$ weeks). In our study phIGFBP-1 test was found to be a useful tool for the prediction of preterm delivery generally (+LR 2.87, 95\% $\mathrm{Cl}$ : 1.57-5.7), which was not investigated by the previous authors. However as the most of twin gestations are delivered prior to 37 weeks, the efficacy of the test in prediction of preterm delivery is of less importance.

The strength of our study is a well characterised cohort of patients in twin gestations from a single centre with defined management protocols. All patients were tested during a limited time interval at 20-24 weeks of gestation. The use of commercially available test for phIGFBP-1 presence is essential in clinical practice. The limitations of the study include a small sample size and lack of blindness of the test results for the managing clinicians. To avoid bias we excluded patients who had Arabin pessary or cervical cerclage applied and there were no clinical decisions made on the phIGFBP-1 test result.

\section{CONCLUSIONS}

In conclusion, a test for phIGFBP1 presence in mid-pregnancy is not an effective additional tool for predicting preterm delivery before 34 weeks in twin gestation.

\section{Acknowledgements}

None.

\section{Disclosure}

Authors declare no conflict of interest.

\section{REFERENCES}

1. Garabedian C, Poulain C, Duhamel A, et al. Intrapartum management of twin pregnancies: are uncomplicated monochorionic pregnancies more at risk of complications than dichorionic pregnancies? Acta Obstet Gynecol Scand. 2015; 94(3): 301-307, doi: 10.1111/aogs.12558, indexed in Pubmed: 25494703.

2. Tarter JG, Khoury A, Barton JR, et al. Demographic and obstetric factors influencing pregnancy outcome in twin gestations. Am J Obstet Gynecol. 2002; 186(5): 910-912, doi: 10.1067/mob.2002.123989, indexed in Pubmed: 12015510.

3. Goldenberg $\mathrm{RL}$, lams JD, Das $\mathrm{A}$, et al. The preterm prediction study: risk factors in twin gestations. National Institute of Child Health and
Human Development Maternal-Fetal Medicine Units Network. Am J Obstet Gynecol. 1996; 175(4 Pt 1): 1047-1053, doi: 10.1016/s00029378(96)80051-2, indexed in Pubmed: 8885774.

4. Bibby E, Stewart A. The epidemiology of preterm birth. Neuro Endocrinol Lett. 2004; 25 Suppl 1: 43-47, indexed in Pubmed: 15735585.

5. Burgess JL, Unal ER, Nietert PJ, et al. Risk of late-preterm stillbirth and neonatal morbidity for monochorionic and dichorionic twins. Am J Obstet Gynecol. 2014; 210(6): 578.e1-578.e9, doi: 10.1016/j. ajog.2014.03.003, indexed in Pubmed: 24607757.

6. Brubaker SG, Gyamfi C. Prediction and prevention of spontaneous preterm birth in twin gestations. Semin Perinatol. 2012; 36(3): 190-194, doi: 10.1053/j.semperi.2012.02.003, indexed in Pubmed: 22713500.

7. Nuutila M, Hiilesmaa V, Kärkkäinen T, et al. Phosphorylated isoforms of insulin-like growth factor binding protein-1 in the cervix as a predictor of cervical ripeness. Obstet Gynecol. 1999; 94(2): 243-249, indexed in Pubmed: 10432136.

8. Kekki M, Kurki T, Kärkkäinen T, et al. Insulin-like growth factor-binding protein-1 in cervical secretion as a predictor of preterm delivery. Acta Obstet Gynecol Scand. 2001; 80(6): 546-551, doi: 10.1080/j.1600-0412.2001.080006546.x, indexed in Pubmed: 11380291.

9. Lembet A, Eroglu D, Ergin T, et al. New rapid bed-side test to predict preterm delivery: phosphorylated insulin-like growth factor binding protein-1 in cervical secretions. Acta Obstet Gynecol Scand. 2002; 81(8): 706-712, doi: 10.1080/j.1600-0412.2002.810804.x, indexed in Pubmed: 12174153.

10. Conde-Agudelo A, Romero R, Hassan SS, et al. Transvaginal sonographic cervical length for the prediction of spontaneous preterm birth in twin pregnancies: a systematic review and metaanalysis. Am J Obstet Gynecol. 2010; 203(2): 128.e1-128.12, doi: 10.1016/j.ajog.2010.02.064, indexed in Pubmed: 20576253.

11. Balić D, Latifagić A, Hudić I. Insulin-like growth factor-binding protein-1 (IGFBP-1) in cervical secretions as a predictor of preterm delivery. J Matern Fetal Neonatal Med. 2008; 21(5): 297-300, doi: 10.1080/14767050802037613, indexed in Pubmed: 18446654.

12. Goyal M, Kriplani A, Kachhawa G, et al. Prediction of preterm labor by a rapid bedside test detecting phosphorylated insulin-like growth factor-binding protein 1 in cervical secretions. Int J Gynaecol Obstet. 2016; 134(2): 165-168, doi: 10.1016/j.ijgo.2016.01.019, indexed in Pubmed: 27233814

13. Elizur SE, Yinon Y, Epstein GS, et al. Insulin-like growth factor binding protein-1 detection in preterm labor: evaluation of a bedside test. Am J Perinatol. 2005; 22(6): 305-309, doi: 10.1055/s-2005-870895, indexed in Pubmed: 16118718.

14. Rahkonen L, Rutanen EM, Nuutila M, et al. Elevated levels of decidual insulin-like growth factor binding protein-1 in cervical fluid in early and mid-pregnancy are associated with an increased risk of spontaneous preterm delivery. BJOG. 2010; 117(6): 701-710, doi: 10.1111/j.1471-0528.2010.02551.x, indexed in Pubmed: 20374609.

15. Cooper S, Lange I, Wood S, et al. Diagnostic accuracy of rapid phIGFBP-I assay for predicting preterm labor in symptomatic patients. J Perinatol. 2012; 32(6): 460-465, doi: 10.1038/jp.2011.133, indexed in Pubmed: 21997470.

16. Kallioniemi $\mathrm{H}$, Rahkonen $\mathrm{L}$, Heikinheimo $\mathrm{O}$, et al. Early pregnancy vaginal fluid phosphorylated insulin-like growth factor binding protein-1 predicts preterm delivery. Prenat Diagn. 2013; 33(4): 378-383, doi: 10.1002/pd.4072, indexed in Pubmed: 23408645.

17. Adeyemi O, Osoba L. The role of phosphorylated insulin-like growth factor binding protein-1 in predicting pre-term labour in twin pregnancies. J Obstet Gynaecol. 2010; 30(6): 571-573, doi: 10.3109/01443615.2010.494203, indexed in Pubmed: 20701504.

18. Fichera A, Prefumo F, Zanardini C, et al. Rapid cervical phIGFBP-1 test in asymptomatic twin pregnancies: role in mid-pregnancy prediction of spontaneous preterm delivery. Prenat Diagn. 2014; 34(5): 450-459, doi: 10.1002/pd.4328, indexed in Pubmed: 24436153. 